\title{
The effect of salsalate on insulin action and glucose tolerance in obese non-diabetic patients: results of a randomised double-blind placebo-controlled study
}

\author{
J. Koska • E. Ortega • J. C. Bunt • A. Gasser • \\ J. Impson • R. L. Hanson • J. Forbes • B. de Courten • \\ J. Krakoff
}

Received: 12 August 2008 / Accepted: 19 November 2008 / Published online: 23 December 2008

(C) The Author(s) 2008. This article is published with open access at Springerlink.com

\begin{abstract}
Aim/hypothesis Low-grade inflammation may contribute to obesity-related insulin resistance and has been associated with increased risk of type 2 diabetes mellitus. The present study evaluated whether treatment with salsalate, a traditional anti-inflammatory medication, would improve insulin action in obese non-diabetic individuals.

Methods The study was a randomised, double-blind, placebocontrolled, parallel trial conducted at the inpatient clinical research unit of the NIDKK (Phoenix, AZ, USA). Participants were 54 adults ( 18 to 45 years of age) with $B M I \geq 30 \mathrm{~kg} / \mathrm{m}^{2}$. The intervention was salsalate ( $3 \mathrm{~g} /$ day, $n=28)$ or identical placebo $(n=26)$ for 7 days. The allocation was kept concealed by giving the investigator only a number corresponding to a vial of placebo or salsalate sequentially randomised in blocks by sex. Main outcomes were changes in insulin action assessed as rate of glucose disposal $\left(R_{\mathrm{d}}\right)$ by euglycaemic-hyperinsulinaemic clamp (insulin infusion rate $40 \mathrm{mU} \mathrm{m}^{-2} \mathrm{~min}^{-1}$ ) and glucose tolerance by $75 \mathrm{~g}$ OGTT.
\end{abstract}

J. Koska and E. Ortega contributed equally to this work.

Electronic supplementary material The online version of this article (doi:10.1007/s00125-008-1239-x) contains supplementary material, which is available to authorised users.

J. Koska $(\bowtie) \cdot$ E. Ortega • J. C. Bunt · J. Impson • R. L. Hanson •

B. de Courten J. Krakoff

Obesity and Diabetes Clinical Research Section,

NIDDK/NIH/DHHS,

4212 N 16th Street,

Phoenix, AZ, USA

e-mail: koskaj@mail.nih.gov

A. Gasser · J. Forbes $\cdot$ B. de Courten

Baker Heart Research Institute \& International Diabetes Institute,

Melbourne, VIC, Australia
Results The study was completed by 47 participants, of which 40 were analysed (salsalate $n=22$, placebo $n=18$ ). Salsalate treatment resulted in decreased fasting plasma glucose concentration (mean [SD]; $4.83[0.28]$ vs 5.11 $[0.33] \mathrm{mmol} / \mathrm{l}, p=0.001)$ and glucose AUC during the OGTT ( $p=0.01)$, and in increased $R_{\mathrm{d}}(20$ [8] vs 18 [6] $\mu \mathrm{mol}$ $\left.[\mathrm{kg} \text { estimated metabolic body size }]^{-1} \min ^{-1}, p=0.002\right)$, while there was no significant change in these variables with placebo ( $p>0.3$ for all). The effect of salsalate on $R_{\mathrm{d}}$ disappeared $(p=0.9)$ after normalising to increased insulin concentrations (701 [285] vs 535 [201] pmol/1, $p<0.0001)$ measured during the clamp. No side effects of salsalate were observed during the study.

Conclusions/interpretation The glucose-lowering potential of salicylates appears to be due to effects on insulin concentration rather than improved insulin action. Salicylate-based compounds may be useful for the treatment and prevention of type 2 diabetes.

Trial registration: ClinicalTrials.gov NCT 00339833.

Funding: Intramural research programme of the NIDDK/ NIH/DHHS.

Keywords Clinical science · Cytokines · Human ·

Insulin sensitivity and resistance .

Prediction and prevention of type 2 diabetes

$\begin{array}{ll}\text { Abbreviations } \\ \text { ANCOVA } & \text { analysis of covariance } \\ \text { CRP } & \text { C-reactive protein } \\ \text { EGP } & \text { endogenous glucose production } \\ \text { EMBS } & \begin{array}{l}\text { estimated metabolic body size } \\ \text { GIR }\end{array} \\ \text { glucose infusion rate } \\ \text { IKK } & \text { IkB kinase }\end{array}$


NF- $\mathrm{kB} \quad$ nuclear factor- $\mathrm{kB}$

PBMC peripheral blood mononuclear cells

$R_{\mathrm{a}} \quad$ rate of glucose appearance

$R_{\mathrm{d}} \quad$ rate of glucose disposal

\section{Introduction}

Obesity is a condition characterised by chronic activation of the innate immune system [1]. This subclinical activation has been implicated in the development of metabolic complications of obesity such as insulin resistance and type 2 diabetes mellitus [2-4]. Treatment of inflammation is a potential novel strategy in prevention and treatment of type 2 diabetes [5].

Administration of salicylates, traditional anti-inflammatory drugs, has been known to reduce hyperglycaemia in patients with pre-existing diabetes [6-8]. Indeed, not only do salicylates reduce fasting systemic glucose concentrations, they also improve systemic glucose concentrations following oral glucose, a mixed meal and an intravenous insulin challenge in diabetic and non-diabetic patients [9-14]. Moreover, in diabetic and non-diabetic patients, improvement of glucose tolerance was observed within 1 week of treatment with aspirin (chemically, acetylsalicylic acid) [10, 12]. In experimental animal models, salicylates lowered plasma glucose and insulin concentrations during an OGTT [15].

The mechanisms underlying the glucose-lowering effect of salicylates have not been defined and studies remain conflicting. In 3T3-L1 adipocytes and $\mathrm{FaO}$ hepatoma cells, pre-treatment with high doses of salicylates reversed TNF$\alpha$-induced cellular insulin resistance [15], while in rats salicylates prevented hepatic and peripheral insulin resistance induced by lipid infusion $[16,17]$. Patients with type 2 diabetes showed decreased endogenous glucose production (EGP) and increased insulin-mediated glucose disposal when administered a high anti-inflammatory dose of acetylsalicylic acid [12]. In healthy participants, acute pretreatment with aspirin attenuated lipid-induced impairment of insulin action [18], but had no effect on insulin resistance induced by prolonged fasting [19]. However, other studies in healthy individuals indicated that the stimulatory effect of salicylates on glucose utilisation is caused by increased systemic availability of insulin, in spite of unchanged or even decreased peripheral insulin sensitivity [20-22].

The nuclear factor- $\mathrm{KB}(\mathrm{NF}-\mathrm{kB})$ has been proposed as a molecular target mediating the glucose-lowering effect of salicylates [5]. NF- $\mathrm{KB}$ is a transcription factor that stimulates expression of numerous genes whose products may alter insulin action [5]. NF- $\mathrm{KB}$ is maintained in the cytoplasm through interaction with inhibitory proteins, the IKBs, which are rapidly degraded upon phosphorylation by IKB kinase (IKK) [23]. The inhibitory effect of salicylates on $\mathrm{NF}-\mathrm{KB}$ activation is presumed to be mediated via inhibition of IKK $\beta$ activity [24]. In fact, administration of salicylates prevented hepatic and peripheral insulin resistance in mice with genetically increased IKK $\beta$ levels in the liver [25].

Since chronic low-grade inflammation is a hallmark of obesity [1] and contributes to increased risk of insulin resistance and type 2 diabetes [4], we investigated whether use of a common anti-inflammatory dose of salsalate $(3 \mathrm{~g}$ per day) in non-diabetic obese individuals (BMI $\geq 30 \mathrm{~kg} / \mathrm{m}^{2}$ ) would improve insulin action as measured by the euglycaemic-hyperinsulinaemic clamp method and whether changes in insulin action were mediated via improvement in inflammation, specifically the NF- $\mathrm{KB} / \mathrm{IKK} \beta$ inflammatory pathway. Salsalate is a dimer of salicylic acid with an established safety profile after many decades of use to treat rheumatic pain, including lower bleeding risk compared with aspirin.

\section{Methods}

Study design

The study was double-blind and placebo-controlled in design. Eligible participants were between 18 and 45 years, had a BMI $\geq 30 \mathrm{~kg} \mathrm{~m}^{-2}$ and were non-diabetic by OGTT (1999 WHO criteria). All participants were non-smokers at the time of the study and, except for obesity, healthy according to medical history, physical examination and routine laboratory tests. The protocol was approved by the Institutional Review Board of the NIDDK and the Gila River Indian Community tribal council. All participants provided written informed consent before participation.

\section{Study procedures}

Upon admission to the clinical research unit at the NIDKK (Phoenix, AZ, USA), all participants were placed on a weightmaintaining diet (containing 50\% of energy as carbohydrate, $30 \%$ as fat and $20 \%$ as protein). Body composition was measured by dual-energy x-ray absorptiometry (GE/Lunar, Madison, WI, USA). At least 3 days after admission and after a $12 \mathrm{~h}$ overnight fast a 2 -h 75 g OGTT was performed to exclude diabetes.

One day after the OGTT, a euglycaemic-hyperinsulinaemic clamp was performed to assess insulin action at physiological hyperinsulinaemia [26]. Briefly, after an overnight fast a catheter was placed in the antecubital vein and a primed (1.11 MBq) continuous $(0.01 \mathrm{MBq} / \mathrm{min})\left[3-{ }^{3} \mathrm{H}\right]$ glucose infusion was started to determine EGP. A second catheter was inserted retrogradely into a vein on the dorsum of the hand for blood sampling and the hand was placed in a heated box 
$\left(60^{\circ} \mathrm{C}\right)$ for the duration of the study. At least $2 \mathrm{~h}$ after starting the $\left[3-{ }^{3} \mathrm{H}\right]$ glucose infusion, a primed continuous intravenous insulin infusion was administered for $100 \mathrm{~min}$ at a constant rate of $40 \mathrm{mU} \mathrm{m}^{-2} \mathrm{~min}^{-1}$. Arterialised blood samples were collected every $5 \mathrm{~min}$ for plasma glucose determination and a $20 \%$ glucose infusion was adjusted to maintain the plasma glucose concentration at about $5.6 \mathrm{mmol} / \mathrm{l}$. Blood samples for measurement of $\left[3-{ }^{3} \mathrm{H}\right]$ glucose specific activity and plasma glucose and serum insulin concentrations were collected at the end of the basal period (22, 15, 8 and $1 \mathrm{~min}$ prior to insulin infusion) and every $10 \mathrm{~min}$ during the final $40 \mathrm{~min}$ of insulin infusion.

Under fasting conditions, the rate of glucose appearance $\left(R_{\mathrm{a}}\right)$ was calculated as the $\left[3-{ }^{3} \mathrm{H}\right]$ glucose infusion rate divided by the steady-state plasma $\left[3-{ }^{3} \mathrm{H}\right]$ glucose specific activity. During the insulin clamp, $R_{\mathrm{a}}$ was calculated from Steele's non-steady-state equation [27]. EGP was calculated as the difference between $R_{\mathrm{a}}$ and the exogenous glucose infusion rate (GIR) corrected for changes in glucose concentrations. The rate of glucose disposal $\left(R_{\mathrm{d}}\right)$ was defined as the average sum of GIR and EGP during the last $40 \mathrm{~min}$ of the insulin infusion. $R_{\mathrm{d}}$ was further corrected for individual variation in average plasma glucose and serum insulin concentrations during the last $40 \mathrm{~min}$ of the clamp $[26,28]$ by normalising to reference values of $5.55 \mathrm{mmol} / 1$ for glucose and $280 \mathrm{pmol} / 1$ for insulin $\left(\sim \mathrm{ED}_{50}\right.$ of insulin-stimulated whole-body glucose disposal standardised to current insulin assay) [29]. GIR, EGP and $R_{\mathrm{d}}$ were further normalised to estimated metabolic body size (EMBS), which is directly derived from fat-free mass but takes into account the intercept of the relation between metabolic rate and fat-free mass $(-17.7 \mathrm{~kg}$ in our laboratory [i.e. $\mathrm{EMBS}=$ fat-free mass $+17.7 \mathrm{~kg}$ ]) [30]. The metabolic clearance rate of insulin was defined as insulin infusion rate divided by incremental (clamp minus basal) serum insulin concentration during the last 40 min of the insulin infusion.

\section{Randomisation}

One day after the clamp, participants were randomly assigned to receive orally $3 \mathrm{~g} /$ day salsalate (Salsalate; Pliva, Zagreb, Croatia) or identical placebo divided in two doses for 7 days. Participants and research personnel were blinded to the assignment. Tolerance of the medication was evaluated daily by questionnaire and monitoring vital signs. The OGTT was repeated on day 6 of medication and the euglycaemic-hyperinsulinaemic clamp was repeated on day 7 with the last dose of the medication being administered $1 \mathrm{~h}$ prior to the start of the insulin infusion. Serum salicylate concentrations were drawn $1 \mathrm{~h}$ prior to the final dose of medication. Out of 54 participants randomised, seven did not complete the second OGTT due to voluntary withdrawal $(n=3$, one of which assigned to salsalate), toothache, indigestion, chest pain and minor infection (all assigned to placebo). Six participants did not complete second clamp because of poor venous access ( $n=$ 4 , two from each treatment group), anaemia or excess drop in glycaemia during insulin infusion $(3.8 \mathrm{mmol} / \mathrm{l})$ (both from the salsalate group). One participant from the salsalate group was not included in the analysis due to an error in preparation of the isotope solution. Details on withdrawals, see Fig. 1 in the Electronic supplementary material (ESM).

\section{Laboratory measurements}

Plasma glucose concentrations were determined by the glucose oxidase method (Beckman Instruments, Fullerton, CA, USA). Insulin concentrations in plasma (OGTT) or serum (clamp) were measured by an automated immunoassay (Access; Beckman Instruments). Commercial ELISA was used to determine concentrations of inflammatory markers (C-reactive protein [CRP] and monocyte chemoattracting protein 1) and adiponectin in plasma (Lincoplex; Millipore, Billerica, MA, USA), and NEFA in serum (Wako Chemicals, Richmond, VA, USA). Serum salicylate concentration was determined by a colorimetric assay from Dade Behring (Milton Keynes, UK).

The activity of the p65 subunit of NF- $\mathrm{kB}$ in isolated monocytes from peripheral blood was measured in a subgroup of 20 participants (ten from each group). Briefly, peripheral blood mononuclear cells (PBMC) were isolated from whole blood using Ficoll-Paque Plus density centrifugation (Amersham Biosciences, Uppsala, Sweden). The PBMC pellet was resuspended in $90 \%$ fetal bovine serum with $10 \%$ DMSO (vol./vol) and stored at $-80^{\circ} \mathrm{C}$ until shipment on dry ice. Thawed PBMC samples were washed in excess PBS ( $\mathrm{pH} 7.4)$ and centrifuged $\left(400 \times g, 5 \mathrm{~min}, 4^{\circ} \mathrm{C}\right)$, to remove residual fetal bovine serum and DMSO. The supernatant fraction was discarded and the pellets resuspended in $100 \mu \mathrm{l}$ of triple detergent buffer $(50 \mathrm{mmol} / \mathrm{l}$ Tris $\mathrm{HCl} \mathrm{pH} 8.0 ; 150 \mathrm{mmol} / 1 \mathrm{NaCl} ; 0.02 \% \mathrm{NaN}_{3} ; 0.1 \%$ SDS; $100 \mu \mathrm{g} / \mathrm{ml}$ PMSF; $1 \mu \mathrm{g} / \mathrm{ml}$ aprotinin; $1 \%$ nonidet P-40; $0.5 \%$ sodium deoxycholate (wt/vol.), in Milli-Q $\mathrm{H}_{2} \mathrm{O}$ [Millipore]). The samples were then sonicated for $1 \mathrm{~min}$ and centrifuged $\left(400 \times \mathrm{g}, 3 \mathrm{~min}, 4^{\circ} \mathrm{C}\right)$. The resulting supernatant fraction was used for the DNA binding assay outlined below to assess p65, NFKB activity. The protein concentration of all protein isolates was determined using a protein assay (Bicinchoninic Acid assay; Pierce, Rockford, IL, USA) performed according to manufacturer's instructions. The TransAM NF-kB DNA-binding activity assay (Active Motif, Carlsbad, CA, USA) was used to detect and quantify the activity of the p65 subunit of NF-KB. Nuclear extracts from PBMC (30 $\mu \mathrm{g}$ protein per well) were analysed for their binding capacity to an NF-KB consensus sequence in labelled DNA in a 96-well plate format. The 

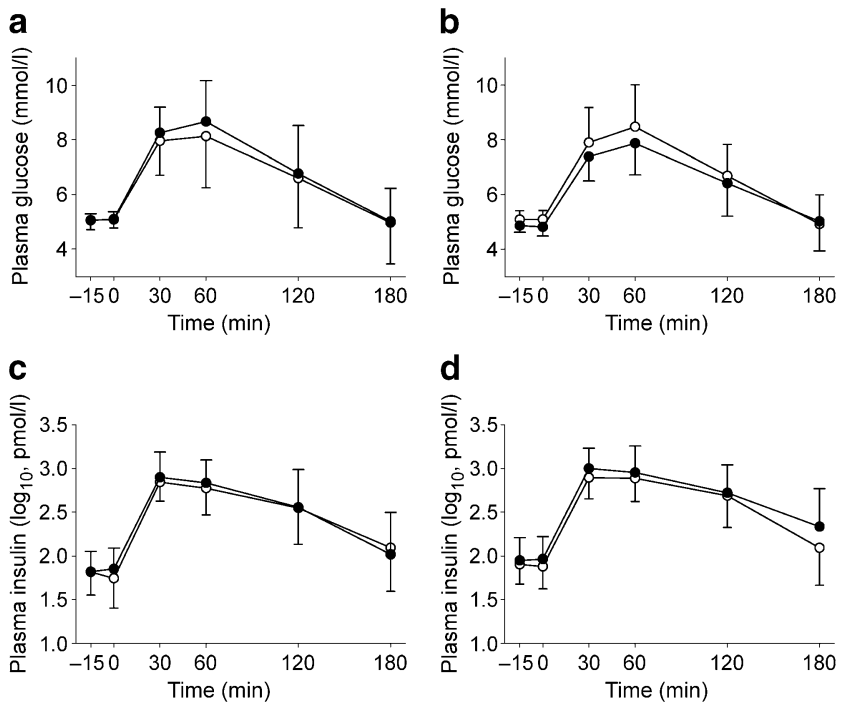

Fig. 1 Plasma glucose and insulin concentrations (means and SD) during an OGTT at baseline (white circles) and after 6 days of treatment (black circles) with placebo $(\mathbf{a}, \mathbf{c})$ or salsalate $(\mathbf{b}, \mathbf{d})$. Repeated-measures ANOVA was used to test for the effects of time ( $p<0.0001$ all models) and visit (follow-up vs baseline; glucose: $p=0.2$ after placebo, $p=0.01$ after salsalate; insulin: $p=1.0$ both), and for the visit $\times$ time interaction within each treatment group (glucose: $p=0.9$ placebo, $p=0.4$ salsalate; insulin: $p=1.0$ both groups). Between-group comparison (ANCOVA): group (placebo vs salsalate) $\times$ visit, $p=$ 0.007 ; group $\times$ visit $\times$ time, $p=0.8$

assays were performed according to manufacturer's instructions. Absorbance was measured on a Victor3 Multilabel plate reader (Perkin Elmer, Wellesley, MA, USA). Results are expressed as ng $\mathrm{p} 65$ activity/ $\mu \mathrm{g}$ protein.

Concentrations of adiponectin and inflammatory markers in plasma, and of NEFA and salicylates in serum, as well as NF- $\mathrm{kB}$ activity in PBMC were measured from fasting blood samples drawn at the baseline OGTT and just prior to the isotope bolus of the second euglycaemic-hyperinsulinaemic clamp.

Sample size calculation

Sample size was estimated using $R_{\mathrm{d}}$ values of obese nondiabetic participants who underwent a euglycaemic-hyperinsulinaemic clamp in a longitudinal study of the aetiology of type 2 diabetes mellitus [31]. Based on recent data (J. C. Bunt, unpublished observation), the log-transformed mean and standard deviation of $R_{\mathrm{d}}$ in this study population was 1.15 and $0.12 \mu \mathrm{mol}\left[\mathrm{kg}_{\mathrm{EMBS}}\right]^{-1} \mathrm{~min}^{-1}$, respectively, and the correlation between two measurements in the same individual was 0.88 . Assuming equal correlation between placebo and treatment groups, the SD of the difference in logarithms of $R_{\mathrm{d}}$ values was calculated as 0.059 . To find a difference of 0.06 in the $\log$ of $R_{\mathrm{d}}$ values, a sample size of 17 in each group was needed to have $80 \%$ power at an alpha of 0.05 .

\section{Statistical analyses}

Statistical analyses were performed using software of the SAS Institute (version 8.02; Cary, NC, USA). Since the primary outcome was the change in $R_{\mathrm{d}}$ from baseline between the salsalate and placebo group, only participants who completed both clamps were included in the analyses. Secondary outcomes were changes in inflammatory markers, glucose tolerance, insulin secretion and hepatic insulin action, as well as the association between the markers of inflammation and metabolic characteristics of the study population. Based on the data distribution, parametric or non-parametric tests were used to compare baseline characteristics of the two groups (unpaired test)

Table 1 Baseline characteristics of the study population by treatment group

\begin{tabular}{|c|c|c|c|}
\hline Characteristic & Placebo & Salsalate & $p$ value \\
\hline$n$ & 18 & 22 & - \\
\hline Men/women $(n)$ & $9 / 9$ & $10 / 12$ & 1.0 \\
\hline Ethnicity $(\mathrm{W} / \mathrm{N} / \mathrm{H})$ & $3 / 14 / 1$ & $3 / 19 / 0$ & 0.6 \\
\hline Age (years) & $33(8)$ & $29(7)$ & 0.2 \\
\hline BMI $\left(\mathrm{kg} / \mathrm{m}^{2}\right)$ & $38(6)$ & $37(5)$ & 0.7 \\
\hline Body fat $(\%)$ & $38(7)$ & $38(6)$ & 0.9 \\
\hline Fasting plasma glucose $(\mathrm{mmol} / \mathrm{l})$ & $5.06(0.33)$ & $5.11(0.33)$ & 0.9 \\
\hline $2 \mathrm{~h}$ plasma glucose $(\mathrm{mmol} / \mathrm{l})$ & $6.61(1.83)$ & $6.67(1.17)$ & 0.9 \\
\hline Fasting plasma insulin (pmol/l) & $63(49,90)$ & $80(56,104)$ & 0.3 \\
\hline Basal EGP $\left(\mu \mathrm{mol}\left[\mathrm{kg}_{\mathrm{EMBS}}\right]^{-1} \mathrm{~min}^{-1}\right)$ & $11(2)$ & $10(2)$ & 0.2 \\
\hline Clamp EGP $\left(\mu \mathrm{mol}\left[\mathrm{kg}_{\text {EMBS }}\right]^{-1} \mathrm{~min}^{-1}\right)$ & $0(0,3)$ & $0(0,2)$ & 0.8 \\
\hline Clamp $R_{\mathrm{d}}\left(\mu \mathrm{mol}\left[\mathrm{kg}_{\mathrm{EMBS}}\right]^{-1} \min ^{-1}\right)^{\mathrm{a}}$ & $16(13,20)$ & $13(11,15)$ & 0.09 \\
\hline
\end{tabular}

Unless otherwise stated, data are means (SD) or medians (25th, 75 th percentile)

${ }^{a} R_{\mathrm{d}}$ normalised for steady-state plasma glucose and serum insulin concentrations

$p$ values were determined by Mantel-Haenszel test on categories, Student's $t$ test on means and Wilcoxon's $U$ test on medians; W, Whites; N,

Native Americans; H, Hispanics 
a
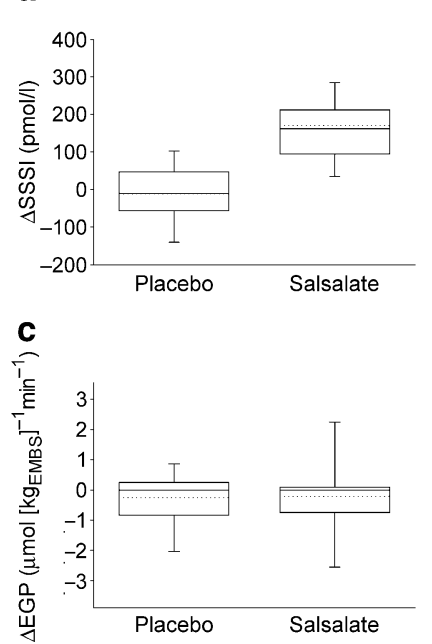

Fig. 2 Changes in: a serum insulin concentration $(\Delta \mathrm{SSSI} ; p=0.6$ placebo, $p<0.0001$ salsalate, follow-up vs baseline by paired $t$ test; $p<$ 0.0001 placebo vs salsalate by ANCOVA); b GIR ( $\Delta \mathrm{GIR} ; p=0.9$ placebo, $p=0.004$ salsalate; $p=0.04$ placebo vs salsalate); c EGP ( $\Delta \mathrm{EGP} ; p=0.3$ placebo, $p=0.5$ salsalate; $p=0.9$ placebo vs salsalate); and $\mathbf{d} R_{\mathrm{d}}\left(\Delta R_{\mathrm{d}}\right.$, adjusted for steady-state glucose; $p=0.7$ placebo, $p=$ 0.003 salsalate; $p=0.02$ placebo vs salsalate) during euglycaemic hyperinsulinaemia after treatment with placebo or salsalate. Data boxes display median (solid line), mean (dotted line), quartiles (box), and 10th and 90th percentiles (error bars)

and to compare the response to treatment within each group (paired test). The effect of two treatments was compared by analysis of covariance (ANCOVA) using the MIXED procedure in SAS. The values of non-normally distributed variables were logarithmically transformed to approximate normal distribution. Spearman correlation was used to test for simple associations between the variables. Two-tailed $p$ values less than 0.05 were considered to be statistically significant.

\section{Results}

A total of 40 participants completed the study, 22 were assigned to salsalate and 18 to placebo. Baseline clinical characteristics of the two groups were not significantly different (Table 1), although it should be noted that there was a trend towards higher $R_{\mathrm{d}}$ in the placebo group. After 7 days of treatment, serum salicylate concentration was increased in all participants receiving salsalate (range 41$232 \mathrm{mg} / \mathrm{l})$ and remained undetectable in all participants treated with placebo $(<14 \mathrm{mg} / \mathrm{l})$ (to convert plasma salicylate values in $\mathrm{mg} / \mathrm{l}$ to $\mathrm{mmol} / \mathrm{l}$ multiply by 0.00724$)$.

Oral glucose tolerance test After the treatment, fasting plasma glucose concentration was significantly decreased in the salsalate group (by mean 4.7 [SD 6.5]\% vs baseline, $p=0.001$ ) and remained unchanged in the placebo group
( $p=0.9)$ ( $p=0.002$ for between-groups comparison). The $2 \mathrm{~h}$ plasma glucose concentration was not significantly changed in any treatment group ( $p=0.2$ salsalate, $p=0.6$ placebo; $p=0.2$ between-groups comparison) (Fig. 1). In repeated measures ANOVA we observed a significant overall lowering of glucose concentrations after treatment in the salsalate group $(p=0.01)$; the effect of treatment on glucose concentration did not significantly vary across the time course of glucose responses to OGTT, i.e. there was no significant treatment $\times$ time interaction (Fig. 1). Administration of placebo or salsalate had no significant effect on plasma insulin concentrations during OGTT (Fig. 1). The effect of salsalate on plasma glucose and insulin concentrations was similar in men and women. Neither changes (follow-up vs baseline) in fasting plasma glucose concentration $(r=0.11$, $p=0.6)$ nor changes in glucose AUC during OGTT $(r=0.01$, $p=1.0$ ) were associated with follow-up serum salicylate concentrations in the salsalate group $(r=0.17, p=0.5)$.

Euglycaemic-hyperinsulinaemic clamp As illustrated by Fig. 2, the average serum insulin concentration during the last $40 \mathrm{~min}$ of the clamp was significantly increased at follow-up in the salsalate group. Metabolic clearance of insulin was decreased after treatment with salsalate $(0.55$ [0.19] vs $0.70[0.22] \mathrm{l} / \mathrm{min}, p<0.0001)$ and unchanged after placebo $(0.80$ [0.27] vs 0.74 [0.17] $1 / \mathrm{min}, p=0.8)$. The salsalate group also showed a significant increase in the GIR (Fig. 2). Because of the unchanged rate of EGP (0.93 [1.84] vs $1.13[1.50] \mu \mathrm{mol}\left[\mathrm{kg}_{\mathrm{EMBS}}\right]^{-1} \mathrm{~min}^{-1}$, follow-up vs baseline, $p=0.5$ ), $R_{\mathrm{d}}$ was also increased after the treatment with salsalate (Fig. 2). The effect of salsalate on clamp insulin concentration, GIR and $R_{\mathrm{d}}$ remained different from the effect of placebo in the between-group comparison (Fig. 2). However, the effect of salsalate on $R_{\mathrm{d}}$ was completely abolished after normalising to average serum insulin concentrations during the clamp $(14[3.61] \mu \mathrm{mol}$
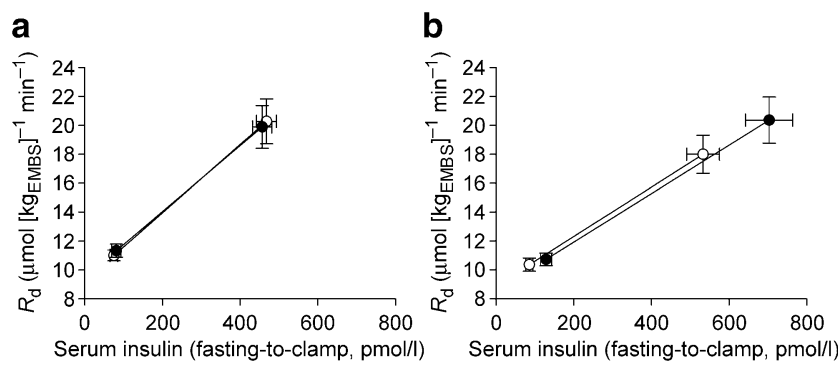

Fig. 3 Change in $R_{\mathrm{d}}$ and serum insulin concentration from fasting state to euglycaemic hyperinsulinaemia at baseline (white circles) and after 7 days of treatment (black circles) with placebo (a) or salsalate (b) demonstrating that the increase in $R_{\mathrm{d}}$ during the clamp is directly associated with the increase in insulin concentration. Fasting $R_{\mathrm{d}}$ was assumed to be equal to the $R_{\mathrm{a}}$ (steady-state assumption) and clamp $R_{\mathrm{d}}$ was equal to $M$ normalised to steady-state plasma glucose concentration. Data are shown as means (SE) 

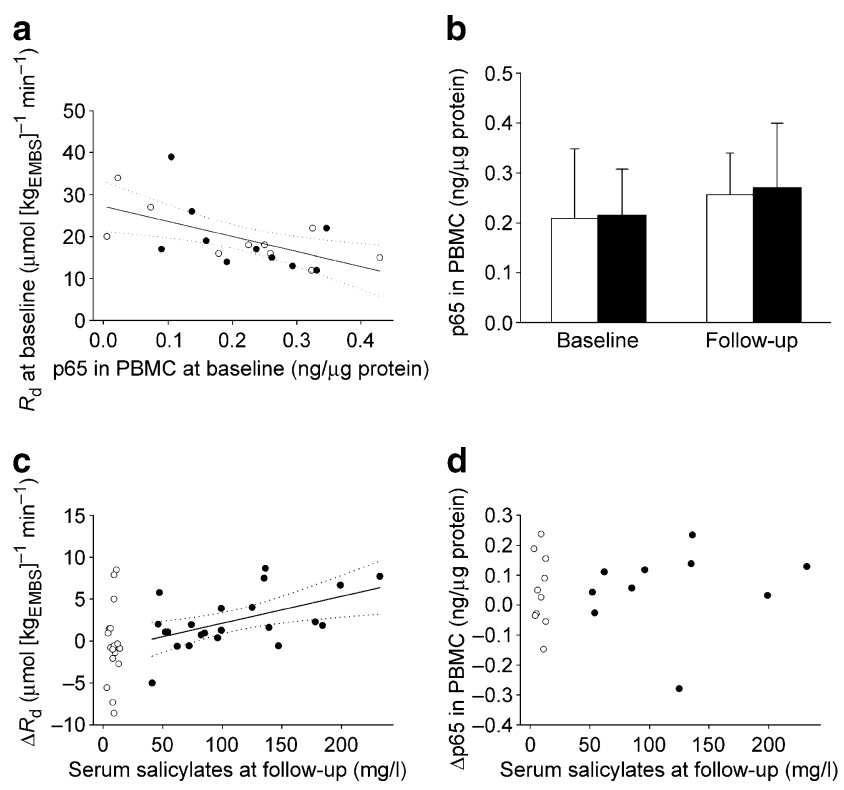

Fig. 4 a Spearman correlation between NF- $k B$ activity (expressed as activity of p65 subunit) and $R_{\mathrm{d}}$ at baseline (normalised to steady-state plasma glucose concentration). $r=-0.56 ; p=0.009$. b The effect of treatment on NF-kB activity ( $n=10$ per group). c Spearman correlation of changes (follow-up minus baseline) in $R_{\mathrm{d}}$ (normalised to steadystate plasma glucose concentration) and (d) NF-KB activity with serum salicylate concentrations at follow-up. $r=0.47, p=0.03$ (c). Black circles/bars, salsalate; white circles/bars, placebo; solid line, linear regression line; dotted line, 95\% CI. (To convert plasma salicylate values in $\mathrm{mg} / \mathrm{l}$ to $\mathrm{mmol} / \mathrm{l}$ multiply by 0.00724 )

$\left[\mathrm{kg}_{\mathrm{EMBS}}\right]^{-1} \mathrm{~min}^{-1}$, follow-up and baseline, $\left.p=0.9\right)$. As illustrated by Fig. 3, the average increase in $R_{\mathrm{d}}$ with salsalate treatment was directly associated with the increase in average insulin concentrations during the clamps, indicating that the higher $R_{\mathrm{d}}$ in the salsalate group was accounted for by the increased insulin concentrations. However, it should also be noted that in a secondary analysis, the difference in $R_{\mathrm{d}}$ between pre- and posttreatment in the salsalate group was positively associated with follow-up serum salicylate concentration both before (Fig. 4) and after normalisation for clamp insulin concen- trations $(r=0.50, p=0.02)$. The effect of treatment on $R_{\mathrm{d}}$ or EGP was not significantly affected by sex.

NEFA, adiponectin and inflammatory markers Neither salsalate nor placebo administration was followed by significant changes in body weight or circulating NEFA concentrations (Table 2). Plasma adiponectin concentration was significantly lower after the 1 week in the placebo group but remained unchanged in the salsalate group (Table 2). Salsalate treatment was followed by a significant decrease in plasma CRP concentration (Table 2). There were no changes in plasma monocyte chemoattracting protein concentration in either group (Table 2). Betweengroup comparisons showed a significant effect of treatment on plasma adiponectin $(p=0.04)$, but not on plasma CRP concentration $(p=0.08)$ and serum activities of aspartate aminotransferase $(p=0.3)$ and alanine aminotransferase $(p=0.5)$. Changes in CRP concentrations in the salsalate group were not significantly related to follow-up serum salicylate concentrations $(r=-0.26, p=0.3)$.

$N F-\kappa B$ activity in PBMC In the subgroup of participants with measurement of activity of the p65 subunit of NF-KB in monocytes from peripheral blood $(n=20$, ten participants in each group), p65 activity was not related to body fat $(r=0.25, p=0.3)$ and was negatively associated with $R_{\mathrm{d}}$ (Fig. 4). The association between p65 activity and $R_{\mathrm{d}}$ at baseline was weaker after normalisation of $R_{\mathrm{d}}$ to average serum insulin concentration during the clamp $(r=0.32$, $p=0.15)$. Treatment with salsalate had no significant effect on p65 activity in monocytes $(p=0.2)$ (Fig. 4). No statistically significant correlation was found between changes in p65 activity and serum salicylate concentrations at followup in the salsalate group $(r=0.43, p=0.09)$. Compared with the whole group, the effect of salsalate on glycaemia was in a similar direction but not significant $(p=0.2)$, while the effect on serum insulin concentration during clamp and $R_{\mathrm{d}}$ ( $p=0.009$, adjusted for glucose; $p=0.4$, adjusted for glucose and insulin) was similar.

Table 2 The effect of placebo or salsalate on metabolic characteristics and inflammatory markers

\begin{tabular}{|c|c|c|c|c|}
\hline \multirow[t]{2}{*}{ Characteristic } & \multicolumn{2}{|l|}{ Placebo $(n=18)$} & \multicolumn{2}{|l|}{ Salsalate $(n=22)$} \\
\hline & Baseline & Follow-up & Baseline & Follow-up \\
\hline Body weight (kg) & $103(89,118)$ & $103(89,117)$ & $109(93,114)$ & $109(93,114)$ \\
\hline NEFA $(\mu \mathrm{mol} / \mathrm{l})$ & $385(320,430)$ & $390(320,440)$ & $345(295,500)$ & $435(385,500)$ \\
\hline Adiponectin (mg/l) & $4.3(3.7,5.7)$ & $3.5(2.8,5.1)^{\mathrm{a}}$ & $5.2(4.0,7.5)$ & $5.2(3.2,6.9)$ \\
\hline hsCRP (ng/l) & $55(33,120)$ & $60(20,108)$ & $63(16,89)$ & $39(12,69)^{\mathrm{a}}$ \\
\hline MCP-1 (ng/l) & $118(99,152)$ & $119(110,132)$ & $109(92,165)$ & $109(80,141)$ \\
\hline
\end{tabular}

Data are medians (25th, 75th percentile)

a $p<0.05$ (Wilcoxon's signed ranks test)

hsCRP, high sensitivity C-reactive protein; MCP-1, monocyte chemoattracting protein 1 


\section{Discussion}

The glucose-lowering effect of salicylates has been known for decades [6-8]. In this randomised double-blind placebo-controlled trial in non-diabetic, healthy obese individuals, administration of a therapeutic dose of salsalate for 1 week decreased fasting plasma glucose (by $\sim 5 \%$ ) as well as glucose, but not insulin concentrations during the OGTT. Salsalate improved apparent peripheral insulin action as measured by glucose disposal during the euglycaemic-hyperinsulinaemic clamp, but this effect was entirely due to increased serum insulin concentrations during the clamp.

Intravenous administration of lysine acetylsalicylate increased insulin concentration in the fasting state and following various secretagogues [32]. A recent placebocontrolled study in non-diabetic individuals showed reduced C-peptide and unchanged insulin response during OGTT in non-diabetic individuals receiving salsalate [13]. Although the authors of that study interpreted these results as improvement in insulin action, their findings could just as well indicate decreased insulin clearance. Treatment with salsalate in our study significantly increased systemic insulin concentration during a euglycaemic-hyperinsulinaemic clamp despite no differences in insulin infusion rates. This is similar to the previously reported effect of aspirin [20], where increased insulin concentrations after aspirin were accompanied by unchanged C-peptide levels indicating lower insulin clearance. Although changes in insulin clearance appear to be the most plausible explanation of increased insulin concentration, incomplete suppression of endogenous insulin production may be an additional contributor. In fact, increasing the dose of the salicylate derivative triflusal was followed by reduced fasting plasma glucose concentration, unchanged insulin effectiveness and augmented insulin response during frequently sampled intravenous glucose tolerance test in a recent double-blind crossover placebo-controlled study in obese non-diabetic individuals [33]. Furthermore, the authors of that study performed additional in vitro experiments supporting a direct stimulatory effect of triflusal on insulin release from beta cells [33].

Normalisation for insulin concentration reflects the fact that whole-body glucose uptake progressively increases with higher rates of insulin infusions and the consequent rise in systemic insulin concentrations within the high physiological range $[29,34,35]$. In our study, $R_{\mathrm{d}}$ was clearly higher following salsalate administration, but normalisation to serum insulin concentrations completely eliminated this difference. It must be noted that in prior studies showing improved insulin action after aspirin in humans the authors either did not report insulin concentrations [18] or did not normalise the $R_{\mathrm{d}}$, which was higher after aspirin treatment compared with baseline, to insulin concentrations [12]. In the latter study, the investigators did perform additional clamp studies in a small subgroup of participants with type 2 diabetes matching the insulin concentrations during clamps performed on and off treatment with aspirin [12]. In this sub-study, they did find an increase in glucose disposal, indicating that the improvement of insulin action might be independent of systemic insulin concentration. The mechanism, however, may not be an anti-inflammatory effect, but could have been secondary to decreased glycaemia.

Although our results showed that the increase in $R_{\mathrm{d}}$ was due entirely to an increase in insulin concentrations, previous experimental data have indicated that the glucose-lowering effect of salicylates was due to improved insulin sensitivity resulting from inhibition of IKK $\beta / N F-k B$ pathway activity and the consequent decrease in production of pro-inflammatory cytokines interfering with insulin action $[15,16,23,24,36]$. Genetic or pharmacological manipulation of IKK $\beta / \mathrm{NF}-\mathrm{KB}$ pathway activity at wholebody or tissue level in experimental animal models was associated with improved peripheral and hepatic insulin action on glucose metabolism [15-17, 25, 37]. However, muscle-specific inhibition of the IKK $\beta / \mathrm{NF}-\mathrm{kB}$ pathway had no effect on a high-fat-induced impairment in peripheral insulin action, while the deletion of $\operatorname{IKK} \beta$ in the myeloid/monocyte cell line did [36]. Consistent with this finding, the NF- $\mathrm{KB}$ activity in isolated monocytes negatively correlated with glucose uptake in a subset of individuals in our study. However, it was unchanged after 1 week of treatment with salsalate. Lack of significant effect of salsalate on plasma glucose concentration in this subset (although the direction of the effect was the same) and the relatively small numbers make some caution necessary when interpreting these data.

We cannot rule out the possibility that with a higher dose and/or longer treatment we might have observed inhibition of NF- $\mathrm{KB}$ activity and a possible improvement of insulin action via this pathway. The salicylate concentrations in our study were below those reported in the study describing improvement of insulin action in participants with type 2 diabetes after 2 weeks of treatment with, on average, $6.2 \mathrm{~g}$ of daily aspirin [12]. We did, however, find that changes in glucose disposal positively correlated with follow-up salicylate levels in participants receiving salsalate. This association indicates that at higher serum salicylate concentrations improvements in insulin action may be partially mediated by pathways (such as NF- $\mathrm{KB}$ ) other than increased concentrations of insulin in the circulation. However, as the salicylate concentration achieved during treatment was not a randomised feature of the present study, potential confounding factors in this association are hard to exclude. The findings from the randomised treatment 
suggest that altered insulin clearance (or secretion) is the primary, clinically meaningful mediator of improvement in glycaemia and increase in $R_{\mathrm{d}}$. Should salicylates at high concentrations improve insulin action, the clinical relevance of this is unclear.

Experiments in rodents have shown that liver-specific inhibition of the IKK $\beta / \mathrm{NF}-\mathrm{kB}$ pathway [36] and treatment with salicylates [17] prevented hepatic insulin resistance. The dose of insulin used in our study was too high to accurately estimate hepatic insulin action. Almost half of all participants in both groups had complete suppression of EGP at baseline and follow-up.

A recent study reported that improvement of glucose tolerance after 4 weeks of treatment with salsalate was accompanied by a significant increase in plasma adiponectin concentration [13]. In our study, adiponectin concentrations were unchanged compared with significant reductions in the placebo group. It is possible that a decrease in physical activity (activities in our inpatient unit during the study are restricted, so participants are more sedentary than in free-living conditions) accounted for the decline in adiponectin concentrations in the placebo, but this was prevented by administration of salsalate.

In conclusion, the results of our study indicate that the primary mechanism for the glucose-lowering effect of a common dose of salicylates appears to be alterations in systemic insulin concentrations. Since reduction of glycaemia is the ultimate goal of treatment and prevention of diabetes, salicylate-based compounds may have potential for treatment or prevention of type 2 diabetes. However, the mechanism by which salicylates increase insulin concentration and lower glucose remains to be determined. Furthermore, the glucose-lowering efficacy of a potential salicylate therapy would assume that the favourable metabolic effects of salicylates would be maintained over a long period of time.

Acknowledgements We acknowledge P. A. Tataranni for an important contribution to study design and initiation, T. Brookshire and the nursing and dietary staffs for the care of the volunteers, and B. Anthony, S. Parrington and E. Spencer for excellent laboratory assistance. We also thank our study participants and members of the Gila River Indian Community. The study was funded by intramural programme of The National Institute of Diabetes and Digestive and Kidney Diseases.

Duality of interest The authors declare that there is no duality of interest associated with this manuscript.

Open Access This article is distributed under the terms of the Creative Commons Attribution Noncommercial License which permits any noncommercial use, distribution, and reproduction in any medium, provided the original author(s) and source are credited.

\section{References}

1. Tataranni PA, Ortega E (2005) A burning question: does an adipokine-induced activation of the immune system mediate the effect of overnutrition on type 2 diabetes? Diabetes 54: 917-927

2. Pickup JC, Crook MA (1998) Is type II diabetes mellitus a disease of the innate immune system? Diabetologia 41:1241-1248

3. Hotamisligil GS (2006) Inflammation and metabolic disorders. Nature 444:860-867

4. Vozarova B, Weyer C, Lindsay RS, Pratley RE, Bogardus C, Tataranni PA (2002) High white blood cell count is associated with a worsening of insulin sensitivity and predicts the development of type 2 diabetes. Diabetes 51:455-461

5. Shoelson SE, Lee J, Goldfine AB (2006) Inflammation and insulin resistance. J Clin Invest 116:1793-1801

6. Ebstein W (1876) Zur Therapie des Diabetes mellitus, insbesondere über die Anwendung des salicylsauren Natron bei demselben. Berliner Klinische Wochenschrift 13:337-340

7. Reid J, Macdougall AI, Andrews MM (1957) Aspirin and diabetes mellitus. BMJ 2:1071-1074

8. Williamson RT (1901) On the treatment of glycosuria and diabetes mellitus with sodium salicylate. BMJ 1:760-762

9. Hecht A, Goldner MG (1959) Reappraisal of the hypoglycemic action of acetylsalicylate. Metabolism 8:418-428

10. Micossi P, Pontiroli AE, Baron SH et al (1978) Aspirin stimulates insulin and glucagon secretion and increases glucose tolerance in normal and diabetic subjects. Diabetes 27:1196-1204

11. Prince RL, Larkins RG, Alford FP (1981) The effect of acetylsalicylic acid on plasma glucose and the response of glucose regulatory hormones to intravenous glucose and arginine in insulin treated diabetics and normal subjects. Metabolism 30:293-298

12. Hundal RS, Petersen KF, Mayerson AB et al (2002) Mechanism by which high-dose aspirin improves glucose metabolism in type 2 diabetes. J Clin Invest 109:1321-1326

13. Fleischman A, Shoelson SE, Bernier R, Goldfine AB (2008) Salsalate improves glycemia and inflammatory parameters in obese young adults. Diabetes Care 31:289-294

14. Gilgore SG, Rupp JJ (1962) The long-term response of diabetes mellitus to salicylate therapy: report of a case. JAMA 180:65-66

15. Yuan M, Konstantopoulos N, Lee J et al (2001) Reversal of obesity- and diet-induced insulin resistance with salicylates or targeted disruption of Ikkbeta. Science 293:1673-1677

16. Kim JK, Kim YJ, Fillmore JJ et al (2001) Prevention of fat-induced insulin resistance by salicylate. J Clin Invest 108:437-446

17. Park E, Wong V, Guan X, Oprescu AI, Giacca A (2007) Salicylate prevents hepatic insulin resistance caused by short-term elevation of free fatty acids in vivo. J Endocrinol 195:323-331

18. Mohlig M, Freudenberg M, Bobbert T et al (2006) Acetylsalicylic acid improves lipid-induced insulin resistance in healthy men. $\mathrm{J}$ Clin Endocrinol Metab 91:964-967

19. van der Crabben SN, Allick G, Ackermans MT, Endert E, Romijn JA, Sauerwein HP (2008) Prolonged fasting induces peripheral insulin resistance, which is not ameliorated by high-dose salicylate. J Clin Endocrinol Metab 93:638-641

20. Bratusch-Marrain PR, Vierhapper H, Komjati M, Waldhausl WK (1985) Acetyl-salicylic acid impairs insulin-mediated glucose utilization and reduces insulin clearance in healthy and noninsulin-dependent diabetic man. Diabetologia 28:671-676

21. Newman WP, Brodows RG (1983) Aspirin causes tissue insensitivity to insulin in normal man. J Clin Endocrinol Metab 57:11021106

22. Giugliano D, Torella R, Siniscalchi N, Improta L, D'Onofrio F (1978) The effect of acetylsalicylic acid on insulin response to glucose and arginine in normal man. Diabetologia 14:359-362 
23. Karin M, Delhase M (2000) The I kappa B kinase (IKK) and NFkappa B: key elements of proinflammatory signalling. Semin Immunol 12:85-98

24. Yin MJ, Yamamoto Y, Gaynor RB (1998) The anti-inflammatory agents aspirin and salicylate inhibit the activity of IкB kinase- $\beta$. Nature 396:77-80

25. Cai D, Yuan M, Frantz DF et al (2005) Local and systemic insulin resistance resulting from hepatic activation of IKK- $\beta$ and NF- $\mathrm{KB}$. Nat Med 11:183-190

26. Lillioja S, Mott DM, Howard BV et al (1988) Impaired glucose tolerance as a disorder of insulin action. Longitudinal and crosssectional studies in Pima Indians. N Engl J Med 318:1217-1225

27. Steele R (1959) Influences of glucose loading and of injected insulin on hepatic glucose output. Ann N Y Acad Sci 82:420-430

28. Best JD, Taborsky GJ, Halter JB, Porte D (1981) Glucose disposal is not proportional to plasma glucose level in man. Diabetes $30: 847-850$

29. Yki-Jarvinen H, Mott D, Young AA, Stone K, Bogardus C (1987) Regulation of glycogen synthase and phosphorylase activities by glucose and insulin in human skeletal muscle. J Clin Invest 80:95-100

30. Lillioja S, Bogardus C (1988) Obesity and insulin resistance: lessons learned from the Pima Indians. Diabetes Metab Rev 4:517-540
31. Bogardus C, Lillioja S, Bennett PH (1991) Pathogenesis of NIDDM in Pima Indians. Diabetes Care 14:685-690

32. Giugliano D, Cozzolino D, Ceriello A et al (1988) Studies on the mechanism of salicylate-induced increase of insulin secretion in man. Diabete Metab 14:431-436

33. Fernandez-Real JM, Lopez-Bermejo A, Ropero AB et al (2008) Salicylates increase insulin secretion in healthy obese subjects. J Clin Endocrinol Metab 93:2523-2530

34. Hother-Nielsen O, Henriksen JE, Holst JJ, Beck-Nielsen H (1996) Effects of insulin on glucose turnover rates in vivo: isotope dilution versus constant specific activity technique. Metabolism 45:82-91

35. Thiebaud D, Jacot E, DeFronzo RA, Maeder E, Jequier E, Felber JP (1982) The effect of graded doses of insulin on total glucose uptake, glucose oxidation, and glucose storage in man. Diabetes 31:957-963

36. Arkan MC, Hevener AL, Greten FR et al (2005) IKK- $\beta$ links inflammation to obesity-induced insulin resistance. Nat Med 11:191-198

37. Rohl M, Pasparakis M, Baudler S et al (2004) Conditional disruption of IKB kinase 2 fails to prevent obesity-induced insulin resistance. J Clin Invest 113:474-481 